УДК 616-002

Доев Д.П.

Северо-Кавказский многопрофильный медицинский центр МЗ РФ

ФГБОУ ВО «Северо-Осетинская государственная медицинская академия»МЗ РФ

\title{
ОПЫТ ПРИМЕНЕНИЯ ГЕМОСОРБЦИОННОЙ КОЛОНКИ СYТОSОRВ В СОСТАВЕ ИНТЕНСИВНОЙ ТЕРАПИИ СЕПТИЧЕСКОГО ШОКА (КЛИНИЧЕСКОЕ НАБЛЮДЕНИЕ)
}

В аспекте интенсивной терапии сепсис по-прежнему является одной из ведущих причин смертности, несмотря на огромные усилия и множество различных видов лечения. По данным некоторых авторов смертность колеблется от 65 до $79 \%[1,2]$. Согласно прогнозам, заболеваемость сепсисом будет ежегодно только увеличиваться [3].

В настоящее время становится все более очевидным недостаточность в улучшении клинических исходов таких краеугольных камней в лечении сепсиса как антибиотикотерапия, контроль инфекции и поддержание огранной перфузии (4).

Одним из ключевых ролей в развертывании медиаторного механизма сепсиса отводится цитокинам. Именно поэтому все чаще в составе интенсивной терапии применяются экстакарпоральные методы лечения. В нашем случае впервые при лечении септического в качестве гемосорбции была использована колонка CytoSorb. Цель ее назначения- быстрое снижение концентрации эндогенных субстанций, поддерживающих системный воспалительный процесс.

Пациент (62 года) в терминальном состоянии на фоне септического шока обусловленного пиелонефритом, был доставлен в приемный покой клиники. После успешного проведения СЛР (сердечно-легочная реанимация) был доставлен в отделение реанимации и интенсивной терапии. Состояние оценивалась как кр тяжелое. По шкале SOFA 11 баллов.

Из-за тяжести состоянии, высокого риска оперативного вмешательства, было решено провести чрескожную пункционную нефростомию, в последующем по стабилизации состояния, нефрэктомию.

В составе интенсивной терапии септического шока, мы традиционно используем продолжительные сеансы (более 12 ч) вено-венозной гемодиафильтрации

Доев Д.П.
(CVVHDF) на стационарном аппарате FRESENIUS Mulitfiltrate. Касательно данного случая, нами в первый день пребывания в отделении реанимации к контуру сета CVVHDF была подключена колонка CytoSorb на 24 часа (рекомендация производителя).

На фоне применения гемосорбции мы отметили значимое снижение маркеров воспалительного процесса уже на вторые сутки интенсивной терапии. Так уровень показателя СРБ снизился на 28\%, уровень лейкоцитов на 39\%, уровень пресепсина на 23\%, уровень гранулоцитов на $30 \%$ (табл.1)

Применение экстракорпоральных методов детоксикации позволило также в более ранние сроки стабилизировать параметры гемодинамики. При чем ощутимое снижение вазопрессорной поддержки мы наблюдали уже по завершению первых суток, что по-видимому связано с уменьшением количества циркулирующих цитокинов (Рис.1)

Острое повреждение почек, наряду с сердечно-сосудистой и респираторной недостаточностью нередко сопровождает септический процесс и особенно септического шок. Проявляется это не только увеличение азотистых шлаков в организме, но и как правило кумулятивным водным балансом, что является независимым фактором 28-дневной летальности. Использование колонку CytoSorb в составе CVVGF, позволило быстро снизить концентрацию эндогенных субстанций до нетоксичного уровня, что по-видимому дает возможность избежать пагубного действия на все органы, включая почки. В нашем случае именно они стали органом «мишенью» септического процесса (табл.2).

Выведение из септического шока, стабилизация витальных функций позволило хирургам в кротчайшие сроки выполнить 
Динамика лабораторных показателей воспалительного процесса

\begin{tabular}{|c|c|c|c|c|c|c|c|c|c|}
\hline Показатели & $\begin{array}{c}1 \\
\text { сутки }\end{array}$ & $\begin{array}{c}2 \\
\text { сутки }\end{array}$ & $\begin{array}{c}5 \\
\text { сутки }\end{array}$ & $\begin{array}{c}7 \\
\text { сутки }\end{array}$ & $\begin{array}{c}9 \\
\text { сутки }\end{array}$ & $\begin{array}{c}11 \\
\text { сутки }\end{array}$ & $\begin{array}{c}13 \\
\text { сутки }\end{array}$ & $\begin{array}{c}15 \\
\text { сутки }\end{array}$ & $\begin{array}{c}17 \\
\text { сутки }\end{array}$ \\
\hline СРБ (мг/л) & 172 & 124 & 135 & 84 & 123 & 37 & 16 & 19 & 18 \\
\hline $\begin{array}{c}\text { Лейкоцит } \\
(109 / л)\end{array}$ & 31 & 19 & 14 & 8 & 11 & 6 & 5 & 6 & 5 \\
\hline $\begin{array}{c}\text { Пресепсин } \\
\text { (пг/мл) }\end{array}$ & 1132 & 872 & 651 & 692 & 483 & 202 & 244 & 155 & 124 \\
\hline $\begin{array}{c}\text { Гранулоциты } \\
(109 / л) ~\end{array}$ & 24,6 & 17,2 & 12,7 & 6,8 & 9,7 & 9,3 & 8 & 7,6 & 7,2 \\
\hline
\end{tabular}



Рис. 1

Вазопрессорная поддержка норадреналином из расчета мкг/кг/мин

Табл.2

Динамика биохимических показателей органной дисфункции

\begin{tabular}{|c|c|c|c|c|c|c|c|c|c|}
\hline Показатепи & $\begin{array}{c}1 \\
\text { сутки }\end{array}$ & $\begin{array}{c}2 \\
\text { сутки }\end{array}$ & $\begin{array}{c}5 \\
\text { сутки }\end{array}$ & $\begin{array}{c}7 \\
\text { сутки }\end{array}$ & $\begin{array}{c}9 \\
\text { сутки }\end{array}$ & $\begin{array}{c}11 \\
\text { сутки }\end{array}$ & $\begin{array}{c}13 \\
\text { сутки }\end{array}$ & $\begin{array}{c}15 \\
\text { сутки }\end{array}$ & $\begin{array}{c}17 \\
\text { сутки }\end{array}$ \\
\hline $\begin{array}{c}\text { Креатинин } \\
\text { (мкмоль/л) }\end{array}$ & 746 & 289 & 228 & 256 & 307 & 222 & 241 & 234 & 256 \\
\hline $\begin{array}{c}\text { Мочевина } \\
\text { (моль/л) }\end{array}$ & 47 & 21 & 24 & 37 & 32 & 14 & 21 & 24 & 22 \\
\hline $\begin{array}{c}\text { АСТ } \\
\text { (МЕ/л) }\end{array}$ & 67 & 50 & 44 & 24 & 22 & 19 & 16 & 19 & 18 \\
\hline $\begin{array}{c}\text { АЛТ } \\
\text { (МЕ/л) }\end{array}$ & 87 & 38 & 36 & 20 & 21 & 20 & 18 & 16 & 16 \\
\hline $\begin{array}{c}\text { Общ } \\
\text { билирубин } \\
\text { (мкмоль/л) }\end{array}$ & 17 & 14 & 14 & 8 & 12 & 11 & 14 & 16 & 12 \\
\hline
\end{tabular}


радикальное оперативное вмешательство (нефрэктомию). Ближайший п/операционный период протекал у пациента гладко, на 19-е сутки он был переведен в профильное отделение.

Таким образом, экстракорпоральное удаление избыточно продуцируемых медиаторов воспаления с помощью гемосорбционной колонки CytoSorb, является эффективным вспомогательным «инструментом» в лечении септического шока.

\section{Литература}

1.Oliveira D. C., de Oliveira F. J. B., Silva R. F. et al. Sepsis in the postoperative period of cardiac surgery: problem description // Arquivos Brasileiros de Cardiologia. - 2010. - Vol. 94, No 3. - P. 332-336, 352-356. http:// www.ncbi. nlm.nih.gov/pubmed/20730262

2. Yaroustovsky M., Abramyan M., Krotenko N. et al. Endotoxin adsorption using polymyxin b immobilized fiber cartridges in severe sepsis patients following cardiac surgery." the international journal of artificial organs.

- 2014. - Vol. 37, No 4. - P. 299-307

3. Карсанов А.М., Маскин С.С., Слепушкин В.Д. Клинико-эпидемиологическое значение системного воспаления и сепсиса// Вестик хирургии.- 2015.- ст 99-103

4. Mayr F. B., Yende S., Angus D. C. Epidemiology of severe sepsis // Virulence. 2014. - Vol. 5, No 1. https://doi.org/10.4161/ VIRU. 27372 